\title{
EVIDENCE THAT THE COMMON STOCK MARKET ADJUSTS FULLY FOR EXPECTED INFLATION
}

\author{
James S. Ang*, Jess H. Chua**, and Anand S. Desai***
}

Inflation has become a major concern for financial managers in recent years because of its effects on company performance. For managers attempting to maximize company value an understanding of how stock prices respond to inflation is of utmost importance.

Stock price may be viewed as the sum of cash flows to stockholders discounted at the required rate of return. Therefore, and understanding of how inflation affects cash flows and required return is necessary for the understanding of how stock prices react to inflation. Considerable attention has been given to the effects of inflation on cash flows to the stockholders. ${ }^{1}$ Unfortunately, the same cannot be said about the response of required rate of return to inflation.

Studies of the response of common stock returns to inflation may be classified into two types. The majority are those concerned with realized returns and whether common stocks are hedges against inflation, e.g., Ibbotson Sinquefield [11] and Reilly [26]. In general, they have shown that common stocks are not complete inflation hedges. The second type deals with required returns and whether they can be explained by the Fisher effect. Works of this type include Jaffee and Mandelker [12], Lintner [19, 20], Nelson [23], and Oudet [24]. In contrast to studies of the bond market, these studies have failed to show the existence of the Fisher effect in the common stock market. This paper is concerned with the second type of problem.

Fisher [8] posited that the ex ante return on an asset must fully reflect the ex ante inflation rate. In symbols:

$$
R=r+I^{*}
$$

where: $R .=$ ex ante nominal return;

$r=$ ex ante real return;

$I^{*}=$ ex ante inflation rate.

The theoretical basis of the Fisher effect has been widely accepted by economists, e.g. Sargent [27]. The existence of the effect in the debt market has been demonstrated empirically by several researchers ${ }^{2}$. For example, Cargill [4] regressed the yield-tomaturity on U.S. government securities $\left(R_{t}\right)$ against expected inflation rates $\left(I_{t}^{*}\right)$ :

$$
R_{t}=a_{0}+C I^{*}+e_{t} .
$$

The results for 1959-1970 showed the regression coefficient, $C$, to be positive and statistically indistinguishable from the theoretical value of unity. On the other hand, tests in

\footnotetext{
*Visiting Professor of Management, Purdue University.

**Associate Professor of Finance, Calgary (University of Calgary).

***Ph.D. candidate, University of Michigan.

${ }^{1}$ A partial listing of recent studies would include Bach and Stephenson [1], Budd and Seiders [2], Cargill [3], Kessel and Alchian [15], Lintner [19], Van Horne and Glassmire [28].

${ }^{2}$ See articles by Cargill [3], Fama [7], Lahiri [17].
} 
the common stock market have not only arrived at regression coefficients significantly different from one, but the regression coefficients obtained were negative in signs. The inconsistency of empirical evidence from the debt and equity markets can be caused by one of two reasons. First, the evidence may be correct and investors in the two markets do not behave similarly. For instance investors in the common stock market may not be behaving in the classical rational sense. This interpretation is difficult to accept, especially in view of the recent evidence on pricing efficiency in the common stock market. Second, the inconsistency may be due to the methodology used by earlier researchers. This latter position is taken in the present study.

This study is concerned with the proof that the Fisher effect does exist in the common stock market. In Section II, a theoretical analysis of the response of common stock returns to inflation rate is presented. The results point out the deficiencies of models used by earlier researchers. Section III proposes a model based on the theoretical results of Section II and presents the embodied hypotheses for empirical testing. Section IV provides the methodology and results of empirical tests. Section $\mathrm{V}$ presents other results related to the hypotheses. Conclusions are offered in Section VI.

\section{The Response of Common Stock Returns to Inflation Rate}

Three assumptions are made in the theoretical analysis. First, common stock prices may be represented by Gordon's [9] constant growth dividend valuation model, i.e.,

$$
P_{t}=\frac{D_{t}\left(1+g_{t}\right)}{R_{t}-g_{t}},
$$

where: $P_{t}=$ observable price of common stock at the beginning of holding period $t$;

$D_{t}=$ observable dividend per share paid on the common stock in the holding period immediately preceeding $t$;

$R_{t}=$ unobservable required nominal return on the common stock formed at the beginning of holding period $t$;

$g_{t}=$ unobservable expected constant growth rate for the dividend payments formed at the beginning of holding period $t$.

Subscripts for $R$ and $g$ signify the time of formation of expectations. $R$ and $g$ are constants in the formulation. Use of the Gordon model should in no way be interpreted as a defense of the relevance of dividend policy. It is used here simply because it is still more popular than the cash flow and investment opportunity models. Although no company pays a constant growth stream of dividends, using a variable dividend model will only increase the algebraic complexity without additional insights.

Second, the Fisher effect is assumed to exist in the common stock market, i.e.,

$$
R_{t}=r+I_{t}^{*}
$$


where $R_{t}$ is as defined earlier, $r$ is the constant required real rate of return, and $I_{t}^{*}$ is the expected inflation rate over the holding period with the expectation formed at the beginning of the holding period $t$.

The constancy of the expected real rate of return is implicit in most empirical studies. It has appeared both as an assumption and a result of the classical theory of interest rate [14] . Empirically, the assumed relationship would be observed if inflation is the dominant factor affecting the required nominal rate of return. Therefore, this assumption may also be seen as an extrapolation to the common stock market of Fama's [7] empirical evidence on the constant required real interest rate. It must be noted that evidence to the contrary has also been found [10].

Third, the expected inflation rate is assumed to vary directly with the unexpected inflation rate, i.e.,

$$
\frac{d^{I^{*}} t+1}{d U_{t}}=\frac{d^{I^{*}} t+1}{d\left(I_{t}-I_{t}^{*}\right)} \geqslant 0 .
$$

where $U_{t}$, the unexpected inflation rate, is equal to $I_{t}-\mathrm{I}_{t}^{*}$ and $I_{t}$ is the actual inflation rate over the holding period $t$. The equality holds when the unexpected inflation is not anticipated to persist.

The second and third assumptions imply that the required nominal return varies directly with the unexpected inflation rate, i.e.,

$$
\frac{d^{R} t+1}{d U_{t}} \geqslant 0
$$

In the debt market, the required nominal return on assets may be approximated by the observed yield-to-matruity. However, the required nominal return in the common stock market, $R_{t}$, is not observable. Instead, what can be observed is the holding period return ( $H P R$, hereafter), defined as:

$$
H P R_{t}=\frac{P_{t+1}-P_{t}+D_{t}}{P_{t}} .
$$

Therefore, a model of the response of common stock returns to the inflation rate must be concerned with the $H P R$ to enable empirical testing. The following development analyzes the implication of the Fisher effect for the response of the HPR to unexpected inflation.

Assume that at the start of a holding period, the common stock market (hereafter, simply market) has set the required real return at $r$ and expects an inflation rate equal to $I_{0}^{*}$. According to the assumed Fisher ${ }_{*}$ effect, the market will set the required nominal return on equity shares at $R_{0}=r+I_{0}^{*}$. On the basis of the dividend paid on the shares in the holding period immediately preceding, $D_{0}$, and the expected constant growth rate of future dividends, $g_{0}$, formed after taking current inflation expectations into account, the price of equity shares, $P_{0}$, will be set such that:

$$
P_{0}=\frac{D_{0}\left(1+g_{0}\right)}{R_{0}-g_{0}} .
$$


If the actual inflation rate is equal to $I_{0}^{*}$, then the required nominal return should remain at $R_{0}$. Ceteris paribus, i.e., keeping $D_{0}$ ang $g_{0}$ constant to isolate the effects of inflation on required return, the price of equity shares at the end of the holding period, $P_{1}^{\prime}$, is:

$$
\begin{aligned}
P_{1}^{\prime} & =\frac{D_{0}\left(1+g_{0}\right)\left(1+g_{0}\right)}{R_{0}-g_{0}} \\
& =P_{0}\left(1+g_{0}\right) .
\end{aligned}
$$

From equation (7), the holding period return to the investors will be:

$$
\begin{aligned}
H P R^{\prime} & =\frac{P_{1}^{\prime}+D_{0}\left(1+g_{0}\right)}{P_{0}}-1 \\
& =\frac{D_{0}\left(1+g_{0}\right)}{P_{0}}+g_{0} .
\end{aligned}
$$

$H P R^{\prime}$ equals the required nominal return, $R_{0}$, set at the beginning of the holding period, as can be seen by solving equation (8) for $R_{0}$. Therefore, all else being constant and if the actual inflation rate is as expected, the holding period return, $H P R^{\prime}$, is equal to the required nominal return, $R_{0}$.

Now, assume that at the end of the holding period, the actual inflation rate, $I_{0}$, is different from the expected inflation rate. This means that the unexpected inflation, $U_{0}$, is nonzero. By equation (6), required nominal return for the following holding period, $R_{1}$, may be different from $R_{0}$.

If the actual dividend paid was $D^{\prime}{ }_{0}$ and the new expected growth rate of dividends is now $g_{1}$, the price of the equity shares should be:

$$
P_{1}=\frac{D_{0}^{\prime}\left(1+g_{1}\right)}{R_{1}-g_{1}} .
$$

For the investors who acquired the shares at the beginning of the holding period, the HPR is then:

$$
H P R=\frac{P_{1}+D_{0}^{\prime}}{P_{0}}-1
$$

Substituting equation (12) into equation (13) yields:

$$
=\frac{\frac{D_{0}^{\prime}\left(1+g_{1}\right)}{R_{1}-g_{1}}+D_{0}^{\prime}}{P_{0}}-1 .
$$

Since $P_{0}$ is set at the beginning of the holding period, unexpected inflation can affect $H P R$ only through $D_{0}^{\prime}, g_{1}$ and $R_{1}$. The response of the $H P R$ to unexpected inflation, represented as the derivative of the $H P R$ with respect to $U_{0}$, is: 
$\frac{d H P R}{d U_{0}}=\frac{\partial H P R}{\partial D_{0}^{\prime}} \frac{d D_{0}^{\prime}}{d U_{0}}+\frac{\partial H P R}{\partial g_{1}} \frac{d g_{1}}{d U_{0}}+\frac{\partial H P R}{\partial R_{1}} \frac{d R_{1}}{d U_{0}}$

Lintner [18] has shown that dividend dollar payments react with long lags and are, hence, insensitive to short-term phenomenon. Therefore, it may be assumed that the dividend payments will not respond significantly to short-term unexpected inflation, i.e.,

$$
\frac{d D_{0}^{\prime}}{d U_{0}}=0
$$

Equation [15] thus becomes:

$$
\begin{gathered}
\frac{d H P R}{d U_{0}}-\frac{\partial H P R}{\partial g_{1}} \frac{d g_{1}}{d U_{0}}+\frac{\partial H P R}{\partial R_{1}} \frac{d R_{1}}{d U_{0}}, \\
=\left[\left(1+R_{1}\right) \frac{d g_{1}}{d U_{0}}-\left(1+g_{1}\right) \frac{d R_{1}}{d U_{0}}\right] D_{0}^{\prime} / P_{0}\left(R_{1}-g_{1}\right)^{2} .
\end{gathered}
$$

By the assumptions stated earlier,

$$
\frac{d R_{1}}{d U_{0}} \geqslant 0
$$

The actual dividend paid cannot be negative. Further, since the expected constant growth rate has to be greater than -100 percent for a nonliquidating firm, the second term on the right hand side $(R H S)$ of equation (16) has to be negative or zero.

In the first term, $\left(1+R_{1}\right)$ is positive. Therefore, if $\frac{d g_{1}}{d U_{0}}$ is negative, the $R H S$ of equation (16) will be negative. The theoretical and empirical studies on the depreciation effect, the wage-price lag and the net debtor effect would suggest that $\frac{d g_{1}}{d U_{0}}$ is negative. ${ }^{3}$ Therefore it may be concluded that:

$$
\frac{d H P R}{d U_{0}}<0
$$

The $R H S$ of equation (16) can still be negative even if $\frac{d g_{1}}{d U_{0}}$ is positive as long as the magnitude of the first term is smaller than that of the second. Various authors $[6,20]$ have suggested that this may be the case.

This result shows that in the presence of positive unexpected inflation, the HPR is less than the ex ante nominal return. Further, it implies that empirical observations of the response of the $H P R$ to unexpected inflation should yield a negative relationship. Similar results are implied in earlier literature (e.g. Lintner $[19,20]$ and Van Horne and Glassmire [28]) although their implications are not fully examined.

\footnotetext{
${ }^{3}$ See footnote 1 .
} 
The analysis indicates that the HPR is not equal to the required return except when the actual inflation rate is equal to the expected inflation rate. Therefore, regressions of $H P R$ versus actual inflation rate in the form:

$$
H P R_{t}=a_{0}+a_{1} I_{t}+e_{t}
$$

or $H P R$ versus proxies of unexpected inflation in the form:

$$
H P R_{t}=a_{0}^{\prime}+a_{1}^{\prime}\left(I_{t}-I_{t}^{*}\right)+e_{t}^{\prime}
$$

are not good tests of the Fisher effect unless researchers are willing to assume that the market could forecast inflation rate perfectly.

In the absence of perfect forecasts, equation (19) may be seen as a linearized version of equation (16). Hence, researchers who regressed $H P R$ against the actual inflation rate or proxies of unexpected inflation should not have been surprised to find negative regression coefficients. Furthermore, the negative regression coefficients obtained did not repudiate the Fisher effect. The negative regression coefficients do not establish the Fisher effect either because a demonstration of the Fisher effect would require not only evidence that the required nominal return increases with increases in the expected inflation rate, but also that the adjustment coefficient, $C$ in equation (2), be equal to 1.0. Since no previous test has attempted to measure this adjustment coefficient, it can be concluded that the existence of the Fisher effect in the common stock market has not yet been adequately tested.

\section{The Empirical Model and Hypotheses}

The existence of the Fisher effect in the stock market implies that:

$$
R_{t}=r+C I^{*}
$$

where $C$ is a parameter that should equal one. If both $R_{t}$ and $I_{t}^{*}$ were observable, then a direct test of the Fisher effect would be possible. $R_{t}$ is definitely not observable. However, if the Fisher effect is correct, i.e., inflation adjustments are the dominant factors affecting the nominal rate of return, then we may describe the observed $H P R_{t}$ as the sum of the unobservable $R_{t}$, the adjustment for unexpected inflation, $U_{t}$, and random errors, $v_{t}$

$$
H P R_{t}=R_{t}+a U_{t}+v_{t}
$$

This is so because the theoretical analysis in section I has shown that, ceteris paribus, the $H P R$ will be equal to $R_{t}$ in the absence of unexpected inflation. On the other hand, if actual inflation happened to be different from that expected, then the observed HPR will have been adjusted for the effects of unexpected inflation.

Substituting equation (20) in equation (21) yields:

$$
H P R_{t}=r+C I_{t}^{*}+a U_{t}+v_{t}
$$


From the definition of $U_{t}$ in the third assumption of the previous section, equation (22) is equivalent to:

$$
H P R_{t}=r+C I_{t}^{*}+a\left(I_{t}-I_{t}^{*}\right)+v_{t} .
$$

Collecting terms yields:

$$
H P R_{t}=r+(C-a) I_{t}^{*}+a I_{t}+v_{t},
$$

which may be rewritten for empirical testing in the form:

$$
H P R_{t}=b_{0}+b_{1} I_{t}^{*}+b_{2} I_{t}+e_{t}
$$

The model can now be directly tested as long as data on $I^{*}$ is available. It embodies several hypotheses:

Hypothesis 1: The $H P R$ varies inversely with unexpected inflation, that is:

$$
b_{2}<0 \text {. }
$$

This hypothesis is based on the theoretical result that the derivative of HPR with respect to $U$ is negative and $b_{2}$ in equation (25) corresponds to a in equation (23).

Hypothesis 2: The Fisher effect exists in the common stock market. In symbols, this is equivalent to:

$$
b_{1}+b_{2}=(C-a)+a=C=1, \text { for the Fisherian hyp- }
$$

othesis.

Hypothesis 3: The intercept, $b_{0}$, should be equal to the average expected real rate of return on common stocks. This hypothesis is based on the observation that $b_{0}$ in equation (25) corresponds to Fisher's constant required real return, $r$, in equation (24). We shall test this hypothesis by observing the consistency of results, i.e. whether tests with different holding periods would yield the same average annual real return.

\section{Methodology and Results}

\section{A. Data}

The test of the proposed empirical model requires observed inflation expectations. Fortunately, this is available in the form of the Livingston series as corrected by Carlson [5]. The series is not entirely without problems. Pesando [25] has shown that the Livingston series does not reflect rational behavior in the Muth [22] sense. Rationality in the Muth sense has two aspects: efficiency and consistency. Pesando found efficiency but not consistency. Pesando's results are suspect, however, because he used the published Livingston series, which is not the true series. Also, the methodology used depends on the assumption that inflation rate has a distributed lag behavior. If the inflation rate does not behave as a distributed lag model, his results are meaningless. Kane and Malkiel [13] have pointed out a more relevant deficiency: Since the forecasters were not all active participants in the market, their forecasts may not have reflected the actual market expectations. Despite the deficiencies, the corrected Livingston series is the only available series of inflation expectations with a long enough history for the purposes of this paper. 
TABLE 1. Comparison of Preliminary Results with Results from Previous Research with the Model: $H P R_{t}=a_{0}+a_{1} I_{t}+e_{t}$

\begin{tabular}{lcc}
\hline \multicolumn{1}{c}{ Study } & $a_{0}$ & $a_{1}$ \\
\hline $\begin{array}{l}\text { Jaffee and Mandelker (1-month holding } \\
\text { period for 1/1965-12/1971) }\end{array}$ & 0.032 & $-6.768^{*}$ \\
\hline $\begin{array}{l}\text { Nelson (1-month holding } \\
\text { period for 1953-1972) }\end{array}$ & No report & $-2.48^{*}$ \\
\hline $\begin{array}{l}\text { This study (8-month holding } \\
\text { period) 1960-1975 }\end{array}$ & $0.160^{*}$ & $-3.985^{*}$ \\
\hline $\begin{array}{l}\text { This study (14-month holding } \\
\text { period) 1960-1975 }\end{array}$ & $0.258^{*}$ & $-3.206^{*}$ \\
\hline
\end{tabular}

* Significant at the 5 percent level.

The Livingston series represents inflation expectations for eight months and 14 months. This circumstance limits the present tests to these two holding periods. The Center for Research in Security Prices $(C R S P)$ stock index was used to represent HPR in the stock market. The change in the Consumer Price Index $(C P I)$ was used to represent actual inflation for the holding periods $\left(I_{t}\right)$. The $H P R$ is obtained from month-end to month-end: in contrast, the $C P I$ is calculated from prices collected at different times of the month. Therefore, a slight mismatching of time periods occurs for the CPI and HPR.

The period chosen for the tests was from 1960 to 1975 . This period was chosen because it is the only period for which the Fisher effect in the debt-capital market has been conclusively shown $[4,17]$.

B. Preliminary Tests

To ascertain the nature of the stock $H P R$ series and the actual inflation series, and to minimize criticism that the test results are due to the data used, we regressed the $H P R$ against the actual inflation rates and compared the results with those from Jaffee and Mandelker [12] and Nelson [23], who also used the CRSP index and CPI in their tests. These are presented in Table 1 . The results show that the impact multipliers as measured with our data for 8-month and 14-month holding periods were -3.985 and -3.206 , respectively, as compared with Nelson's -2.48 and Jaffee and Mandelker's -6.768 . The data used here thus appear comparable to those used in previous studies.

C. Testing the Hypotheses

The 8-month HPR and the 14-month HPR were calculated from the CRSP index. These were regressed against the 8-month Livingston forecasts and actual 8-month inflation and the 14-month Livingston forecasts and actual 14-month inflation, respectively:

$$
H P R_{t}=b_{0}+b_{1} I_{t}^{*}+b_{2} I_{t}+e_{t}
$$

where: $H P R_{t}=$ holding period return on the CRSP index;

$$
\begin{aligned}
I^{*} & =\begin{array}{l}
\text { Livingston forecasts at the beginning of the } \\
\text { holding period; }
\end{array} \\
I_{t} \quad= & \begin{array}{l}
\text { actual inflation observed for the holding } \\
\text { period; and }
\end{array}
\end{aligned}
$$


TABLE 2. Tests of the Fisher Effect for the Period 1960-1975 with the Model:

$$
H P R_{t}=b_{0}+b_{1} I_{t}^{*}+b_{2} I_{t}+e_{t}
$$

\begin{tabular}{lcccccc}
\hline $\begin{array}{l}\text { Holding } \\
\text { period }\end{array}$ & $b_{0}$ & $b_{1}$ & $b_{2}$ & $R^{2}$ & $D_{1} W_{1}$ & $b_{1}+b_{2}$ \\
\hline 8-month & $\begin{array}{c}0.117^{*} \\
(2.36)\end{array}$ & $\begin{array}{c}12.33^{*} \\
(2.88)\end{array}$ & $\begin{array}{c}-11.39^{*} \\
(-3.89)\end{array}$ & 0.37 & 2.07 & $\begin{array}{c}0.94^{* *} \\
(-0.01)^{* * *}\end{array}$ \\
\hline 14-month & $\begin{array}{c}0.191^{*} \\
(2.79)\end{array}$ & $\begin{array}{c}8.21^{*} \\
(2.44)\end{array}$ & $\begin{array}{c}-7.24^{*} \\
(-3.69)\end{array}$ & 0.36 & 1.27 & $\begin{array}{c}0.97^{* *} \\
(-0.01)^{* * *}\end{array}$ \\
\hline
\end{tabular}

(Thirty-two observations for the 8-month holding period test, 16 observations for the 14-month holding period test $t$-values.)

( ) $t$-values are enclosed in parentheses.

* Significantly different from zero at the 5 percent level.

**Insignificantly different from 1.0 at the 5 percent level.

*** $t$-statistics calculated as:

$$
\frac{\left(b_{1}+b_{2}\right)-1}{\sqrt{S^{2} b_{1}+S^{2} b_{2}}}
$$

$e_{t} \quad=$ random error satisfying the classical regression assumptions.

The results are presented in Table 2 and they indicate that the hypotheses of this study cannot be rejected:

$\mathrm{H} 1: b_{2}<0$. This fact is confirmed for both holding periods at the five percent level.

$\mathrm{H} 2: b_{1}+b_{2}=1$. The resulting sum for the test on 8-month holding period was 0.94 , and for the 14-month holding period, it was 0.97 .

Since all the regression coefficients are statistically significant, the results constitute remarkable support for the existence of the Fisher effect in the common stock market. A test of the null hypothesis that $b_{1}+b_{2}$ is equal to one yielded the $t$-values of -0.01 for both the 8-month and 14-month holding period coefficients. This result shows that the sums are not statistically different from the theoretical value of one.

The large magnitude of $b_{2}$ is reasonable for two reasons. First, the results of previous researchers shown in Table 1 would indicate that the magnitude of the impact multiplier should be about five on average. However, the models used to arrive at Table 1 obviously had a specification error if the model proposed here is correct. The specification error committed would tend to cause an upward bias on the coefficient estimates. (See Kmenta [16, p. 393.] ) This means that the true impact multiplier should be algebraically less than -5 . Second, it is possible to show with equation (16) that the order of magnitude of the impact multiplier should be 10 .

Remember that equation (16) is:

$\frac{d H P R}{d U_{0}}=\left[\left(1+R_{1}\right) \frac{d g_{1}}{d U_{0}}-\left(1+g_{1}\right) \frac{d R_{1}}{d U_{0}}\right] D_{0}^{\prime} / P_{0}\left(R_{1}-g_{1}\right)^{2}$. 
Since $P_{0}=D_{0}\left(1+g_{0}\right) /\left(R_{0}-g_{0}\right)$, the order of magnitude of the term, $D_{0}^{\prime} /$ $P_{0}\left(R_{1}-g_{1}\right)^{2}$ is the same as that of the term, $1 /\left(R_{1}-g_{1}\right)$. Next, assume that the inflation expectations are formed according to an adaptive-expectation process, despite the restrictiveness of the assumption required to make the process satisfy rationality conditions [21]. Then, we may write:

$$
\begin{aligned}
R_{1} & =r+I_{1}^{*} \\
& =r+I^{*}{ }_{0}+\alpha\left(I_{0}-I_{0}\right) .
\end{aligned}
$$

Therefore:

$$
\frac{d R_{1}}{d U_{0}}=\frac{d R_{1}}{d\left(H_{0}-I_{0}^{*}\right)}=\alpha
$$

The results by Lahiri [17] and Van Horne [28] would indicate that $\alpha$ is about 0.7. If we

assume that $\frac{d H P R}{d \bar{U}_{0}}$ is of the order of magnitude one, then the order of magnitude of the derivative $\frac{d H P R}{d U_{0}}$ should be the same as that of the term:

$$
\left[\left(1+R_{1}\right)-0.7\left(1+g_{1}\right)\right] /\left(R_{1}-g_{1}\right) .
$$

Since $\left(R_{1}-g_{1}\right)$ is of order of magnitude 0.01 , then the derivative should have the order of magnitude of $(0.1 / 0.01)=10$.

Since the expected inflation, $P^{*}$, and actual inflation, $I$, are definitely correlated, a multicollinearity problem exists in the tests. Therefore, we should be cautious in interpreting the point estimates obtained since errors could be quite large. The standard errors for the sum $\left(b_{1}+b_{2}\right)$ were 5.16 and 3.89 for the 8-month and 14-month HPR tests, respectively. The formulas used to obtain these numbers are in Table 2.

Another distrubing fact about the results is the low Durbin-Watson statistic obtained in the 14-month HPR test. This indicates significant autocorrelation in the residuals. Since the same problem did not arise in the 8-month HPR test, this leads us to believe that the autocorrelation may have resulted from the constant real rate assumption in the model. This assumption may be adequate for the 8-month HPR test but not for the 14 month $H P R$ test because of the longer holding period involved. If changes in the real rate are small compared to the real rate itself, there should be high autocorrelation in the real return. The missing explanatory variable for the real rate could create the low Durbin-Watson statistic observed for the 14-month HPR test.

H3: The intercept from the test on 8-month HPR's was 0.117 , and 0.191 for the test on 14-month $H P R$ 's. They are equivalent to annual returns of 0.159 and 0.161 , respectively. Therefore, the average required real rate of return obtained from the two tests are consistent. 
TABLE 3. Tests of the Fisher Effect for the Period 1947-59 with the Model:

$$
H P R_{t}=b_{0}+b_{1} I_{t}^{*}+b_{2} I_{t}+e_{t}
$$

\begin{tabular}{lcccc}
\hline $\begin{array}{l}\text { Holding } \\
\text { period }\end{array}$ & $b_{0}$ & $b_{1}$ & $b_{2}$ & $R^{2}$ \\
\hline 8-month & $0.095^{*}$ & -1.508 & 0.194 & 0.04 \\
& $(2.83)$ & $(-0.22)$ & $(1.35)$ & 0.00 \\
\hline 14-month & $0.177^{*}$ & -0.115 & 0.101 & $(1.52)$ \\
& $(4.55)$ & $(-0.04)$ & 0.000 \\
\hline
\end{tabular}

Twenty-six observations for 8-month $H P R$ test; 13 observations for 14-month $H P R$ test $t$-values are enclosed in parentheses.

* Significant at the 5 percent level.

The real-rate estimates are quite low, however. The numbers seem reasonable if we are willing to accept the often-made argument that, in an efficient market, the ex post return should be an unbiased estimate of the ex ante return. Ibbotson and Sinquefield [11] have measured the ex post annual real return on common stocks for 1960-1974 to be 0.33 percent. Although the values obtained here are approximately half of their estimate, the order of magnitude is the same.

\section{Other Results}

Studies of the debt market have shown that while the Fisher effect is observable in the 1960 's and 1970's, it is not observable in the 1940's and 1950's. Tests were also conducted here to verify whether the same phenomenon exists in the stock market. The results are presented in Table 3 . They show that all the regression coefficients were statistically insignificant. Therefore, the model explained nothing about the behavior of common stock returns within this period. This confirms the results from the debt market that the Fisher effect was inoperative during the 1940's and 1950's.

The explanation that has been given usually concerns the institutionalized inflation in the 1960's and 1970's. It has been argued that because the causes of inflation in the 1940's and 1950's were identifiable and not expected to persist, the capital markets did not respond to inflation. In the 1960's and 1970's, however, the realization that a fiscal policy disallowing high unemployment and implying continuous inflation has led to the observed reaction.

\section{Summary and Conclusions}

This paper was directed toward testing for the existence of the Fisher effect in the common stock market. It first analyzed how the observable holding period return should respond to unexpected inflation if the Fisher effect exists. The theoretical results led to the conclusion that the empirical tests of previous researchers did not constitute appropriate tests of the Fisher effect. Further, they showed that the results derived by earlier researchers did not disprove the existence of the Fisher effect in the common stock market, although they did not prove its existence either. A new empirical model based on theoretical analysis was developed and tested. The results fully confirmed the existence of 
the Fisher effect in the common stock market for the period 1960-1975. Consistent with studies on the bond market, the results also failed to demonstrate the existence of the Fisher effect in the period 1947-1959.

This study has therefore shown that the common stock market fully adjusts for expected inflation. This makes responses of investors in the debt and equity markets to inflation rate the same. The inconsistency observed by earlier researchers is resolved.

Although we are tempted to make statements concerning the efficiency of the stock market with respect to expected inflation, we shall not do so. The reason is that we do not have a model of how inflation expectations are formed. Without such a model, we cannot reconcile the results from the 1940's and 1950's with those from the 1960's and 1970 's.

\section{REFERENCES}

1. G. L. Bach, and J. B. Stephenson, "Inflation and the Redistribution of Wealth," Review of Economics and Statistics (February 1974), 1-13.

2. E. C. Budd, and D. F. Seiders, "The Impact of Inflation on the Distribution of Income and Wealth," American Economic Review (May 1971), 128-138.

3. T. F. Cargill, "An Empirical Investigation of the Wage-Lag Hypothesis," American Economic Review (December 1969), 806-816.

4. T. F. Cargill, "Anticipate Price Changes and Nominal Interest Rates in the 1950's," Review of Economics and Statistics (August 1976), 364-367.

5. J. Carlson, "A Study of Price Forecasts," Annals of Economic and Social Measurement (Winter 1977), 27-56.

6. A. H. Chen, and A. J. Boness, "Effects of Uncertain Inflation on the Investment and Financing Decisions of a Firm," Journal of Finance (May 1975), 469-483.

7. E. F. Fama, "Short-Term Interest Rates as Predictors of Inflation," American Economic Review (June 1975), 269-282.

8. I. Fisher, The Theory of Interest, NY: MacMillan, 1930.

9. M. Gordon, The Investment, Financing and Valuation of the Corporation, (Homewood, Ill.: Richard D. Irwin, Inc., 1962).

10. P. J. Hess, and J. L. Bicksler, "Capital Asset Prices Versus Time Series Models as Predictors of Inflation," Journal of Financial Economics (December 1975), 341-360.

11. R. G. Ibbotson, and R. A. Sinquefield, "Stocks, Bonds, Bills, and Inflation: Year-by-Year Historical Returns (1926-1974)," Journal of Business (January 1976), 11-47.

12. J. F. Jaffe, and G. Mandelker, "The 'Fisher Effect' for Risky Assets: An Empirical Investigation," Journal of Finance (May 1976), 447-458.

13. E. J. Kane, and B. G. Malkiel, "Autoregressive and Nonautoregressive Elements in Cross-Section Forecasts of Inflation," Econometrica (January 1976), 1-16.

14. E. Karni, "Inflation and Real Interest Rate: A Long-Term Analysis," Journal of Political Economy (March-April 1972), 365-374.

15. R. A. Kessel, and A. A. Alchian, "Effects of Inflation," Journal of Political Economy (December 1962), 521-537.

16. J Kmenta, Elements of Econometrics, New York: MacMillan, 1971.

17. K. Lahiri, "Inflationary Expectations: Their Formation and Interest Rate Effects," American Economic Review (March 1976), 124-131.

18. J. Lintner, "Distribution of Incomes of Corporations Among Dividends, Retained Earnings and Taxes," American Economic Review (May 1956), 97-113.

19. J. Lintner, "Inflation and Common Stock Prices in a Cyclical Context," NBER 53rd Annual Report, 1973.

20. J. Lintner, "Inflation and Security Returns," Journal of Finance (May 1975), 259-280.

21. M. Mussa, "Adaptive and Regressive Expectations in a Rational Model of the Inflationary Process," Journal of Monetary Economics (October 1975), 423-442. 
22. J. F. Muth, "Rational Expectations and the Theory of Price Movements," Econometrica (July 1961), 315-335.

23. C. Nelson, "Inflation and Rates of Return on Common Stocks," Journal of Finance (May 1976), 471-483.

24. B. A. Oudet, "The Variation of the Return on Stocks in Periods of Inflation," Journal of Financial and Quantitative Analysis (March 1973), 247-258.

25. J. Pesando, "A Note on the Rationality of the Livingston Series on Price Expectations," Journal of Political Economy (August 1975), 849-858.

26. F. K. Reilly, "Companies and Common Stocks as Inflation Hedges," The Bulletin (1975-2), New York University.

27. Thomas J. Sargent, "Interest Rates and Expected Inflation: A Selective Summary of Recent Research," NBER Explorations (Summer, 1976), 303-325.

28. J. C. Van Horne, and W. F. Glassmire, Jr., "The Impact of Unanticipated Changes in Inflation on the Value of Common Stocks," Journal of Finance (December 1972), 1081-1092.

29. W. P. Yohe, and D. S. Karnosky, "Interest Rates and Price Level Changes, 1952-1969," FRB of St. Louis Monthly Review (December 1969), 18-38. 